\title{
GRUPO CONTARTE: NOVOS CAMINHOS PELO TEXTO LITERÁRIO EM TEMPOS DE ISOLAMENTO SOCIAL
}

\author{
CONTARTE GROUP: NEW PATHS THROUGH THE LITERARY TEXT IN TIMES OF SOCIAL \\ ISOLATION
}

\author{
GRUPO CONTARTE: NUEVOS CAMINOS A TRAVÉS DEL TEXTO LITERARIO EN TIEMPOS \\ DE AISLAMIENTO SOCIAL
}

Cleide Jussara Müller Pareja1

\begin{abstract}
RESUMO
A arte de contar histórias é uma prática milenar e que ao longo do tempo criou diferentes contornos e formas de ser. O ContArte, projeto de contação de histórias da Universidade do Vale do Itajaí - UNIVALI, vinculado ao PROLER, atua desde 2003 com foco na educação estética e leitora de crianças, jovens e adultos. $\mathrm{O}$ grupo de contadores tem como objetivo promover o texto literário em ambientes educativos formais e não formais por meio de contações de histórias, rodas de leitura e formação de professores, além de possibilitar 0 acesso ao livro. 0 objetivo deste artigo é discutir sobre as práticas e os recursos adotados pelos contadores de histórias para atuarem em meio à pandemia do COVID-19, uma vez que a universidade precisou suspender as atividades presenciais. Definiu-se como problema de pesquisa: Como o grupo ContArte, em tempos de isolamento social, promoveu o acesso a leitura do literário? Espera-se que os resultados apontem quais mediações efetivaram 0 acesso ao texto literário no meio virtual. A metodologia utilizada foi a pesquisa qualitativa de intervenção e a análise quanti-qualitativa dos dados coletados na rede social Facebook do projeto. $O$ grupo manteve as reuniões semanais em formato online por intermédio da plataforma BlackBoard, disponibilizada pela própria instituição de ensino. A partir desses encontros foram definidos novos meios para cumprir a missão de promover o acesso a leitura do literário. Deste modo, conclui-se que, apesar de muitas adaptações, o grupo continuou seu processo de difundir a leitura literária, com o uso dos meios digitais.
\end{abstract}

PALAVRAS-CHAVE: Contação de histórias; mediação de leitura; isolamento social.

\begin{abstract}
The art of storytelling is an ancient practice that over time has created different outlines and ways of being. ContArte, a storytelling project at the University of Vale do Itajai - UNIVALI, linked to PROLER, has been operating since 2003 with a focus on aesthetic education and reading for children, young people and adults. The group of accountants aims to promote literary text in formal and non-formal educational environments through storytelling, reading circles and teacher training, in addition to providing access to the book. The purpose of this article is to discuss the practices and resources adopted by storytellers to act in the midst of the COVID-19 pandemic, since the university had to suspend face-to-face activities. It was defined as a research problem: How did the ContArte group, in times of social isolation, promote access to literary reading? It is expected that the results show which mediations made access to the literary text in the virtual environment. The methodology used was the qualitative research of intervention and the quantitative and qualitative analysis of the data collected in the social network Facebook of the
\end{abstract}

\footnotetext{
1 Possui Graduação em Letras pela Fundação Educacional do Norte Catarinense (1977), Mestrado em Letras pela Universidade Federal de Santa Catarina (1997). Doutoranda em Educação pela UNIVALI (2018). Atualmente é professora da Universidade do Vale do Itajaí, Membro do Grupo de Pesquisa Cultura, Escola e Educação Criadora. Coordenadora do Grupo CONTARTE do Programa PROLER/UNIVALI. Membro do Projeto de Extensão Mãos de Vida da Escola de Ciências da Saúde. Atua, principalmente, nos seguintes temas: leitura, formação de leitores, formação continuada em leitura, literatura, contação de histórias e língua portuguesa. E-mail: cleidepareja@hotmail.com

Revista de Ciências Humanas, Frederico Westphalen - RS, v. 22, n.2, p. 83-95, maio/ago. 2021. 
project. The group held weekly meetings in an online format through the BlackBoard platform, made available by the educational institution itself. From these meetings, new means were defined to fulfill the mission of promoting access to literary reading. Thus, it is concluded that, despite many adaptations, the group continued its process of spreading literary reading, with the use of digital media.

KEYWORDS: Storytelling; reading mediation; social isolation.

\section{RESUMEN}

El arte de contar historias es una práctica milenaria que con el tiempo ha ido creando diferentes contornos y formas de ser. ContaArte, un proyecto de narración de cuentos de la Universidad de Vale do Itajaí - UNIVALI, vinculado a PROLER, opera desde 2003 con un enfoque en la educación estética y lectora para niños, jóvenes y adultos. El grupo de contadores tiene como objetivo promover el texto literario en entornos educativos formales y no formales a través de la narración, los círculos de lectura y la formación del profesorado, además de facilitar el acceso al libro. El propósito de este artículo es discutir las prácticas y recursos adoptados por los narradores para actuar en medio de la pandemia COVID-19, ya que la universidad tuvo que suspender las actividades presenciales. El problema de investigación se definió como: Cómo el grupo ContArte, en tiempos de aislamiento social, promovió el acceso a la lectura literaria? Se espera que los resultados indiquen qué mediaciones afectaron el acceso al texto literario en el entorno virtual. La metodología utilizada fue la investigación de intervención cualitativa y el análisis cuantitativo-cualitativo de los datos recogidos en la red social Facebook del proyecto. El grupo mantuvo las reuniones semanales en formato online a través de la plataforma BlackBoard, proporcionada por la propia institución educativa. A partir de estos encuentros se definieron nuevos medios para cumplir con la misión de promover el acceso a la lectura literaria. Así, se concluye que, a pesar de muchas adaptaciones, el grupo continuó su proceso de difusión de la lectura literaria, utilizando medios digitales.

PALABRAS-CLAVE: Storytelling; mediación de lectura; aislamiento social.

\section{INTRODUÇÃO}

"Nada do que foi será de novo do jeito que já foi um dia.

Tudo passa, tudo sempre passará" Lulu Santos

A arte de contar histórias é uma prática milenar e que ao longo do tempo criou diferentes contornos e formas de ser. O ContArte, projeto de contação de histórias da Universidade do Vale do Itajaí - UNIVALI, vinculado ao PROLER (Programa Nacional de Incentivo à Leitura) atua desde 2003, com foco na educação estética e leitora de crianças, jovens e adultos. $\mathrm{O}$ grupo de contadores tem como objetivo promover 0 texto literário em ambientes educativos, formais e não formais por meio de contações de histórias, rodas de leitura e formação de professores, além de possibilitar o acesso ao livro, a formação de leitores e a interação sensível pela palavra poética entre as pessoas.

Todavia, o ano de 2020 foi marcado pela pandemia decorrente do novo Coronavírus (COVID 19), o qual impôs novas rotinas, como, por exemplo, suspendeu as modalidades de estudo e trabalho presenciais. Como parte desse cenário, o grupo ContArte também mudou e inaugurou a prática das atividades remotas.

Revista de Ciências Humanas, Frederico Westphalen - RS, v. 22, n.2, p. 83-95, maio/ago. 2021. 
Já que as atividades de ensino, pesquisa e extensão na universidade precisaram ser repensadas, questiona-se: Como o projeto ContArte, em tempos de isolamento social, promoveu o acesso a leitura do literário? A partir dessa problemática, esta pesquisa propõe uma investigação sobre as práticas e os recursos adotados pelos contadores de histórias para atuarem durante o período de isolamento social, em decorrência da COVID-19.

O grupo, composto por dois bolsistas e três voluntárias, manteve as reuniões semanais em formato online em atenção às medidas de cuidado individual e coletivo, por intermédio da plataforma BlackBoard, disponibilizada pela própria instituição de ensino. A partir desses encontros foram definidos novos meios para cumprir a missão de promover o acesso a leitura do literário.

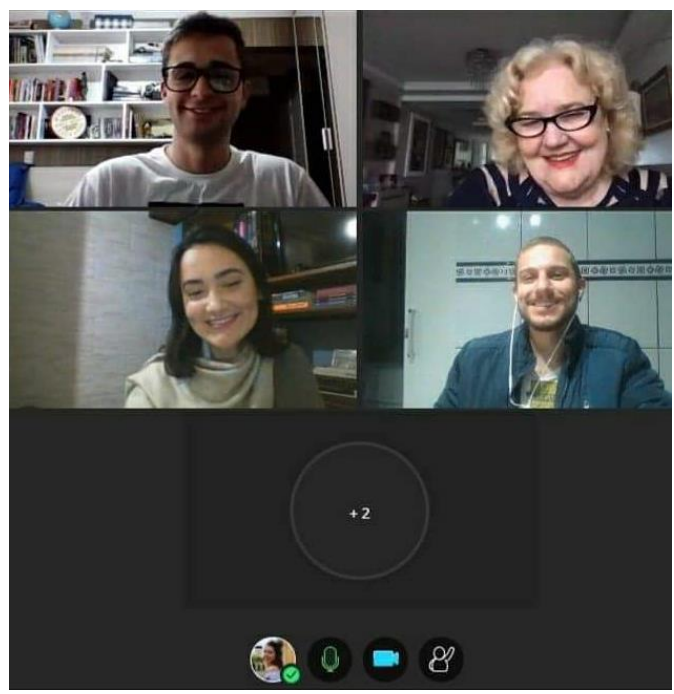

Figura 1 - Reunião do grupo ContArte

Fonte: Acervo das autoras

\section{PERCURSO METODOLÓGICO}

O presente estudo foi desenvolvido a partir das atuações do projeto ContArte no período de isolamento social em decorrência da pandemia da COVID-19. Esta é uma pesquisa qualitativa de intervenção, pois, na pesquisa-intervenção, o pesquisar e o intervir são processos que ocorrem simultaneamente, são indissociáveis. Buscando conhecer um pouco melhor sobre 0 possível alcance das ações do grupo, foi realizada uma coleta de dados na rede social Facebook do projeto, na qual foi empregada uma análise com abordagem quanti-qualitativa.

\section{A CONTAÇÃO DE HISTÓRIAS E A TECNOLOGIA}

Revista de Ciências Humanas, Frederico Westphalen - RS, v. 22, n.2, p. 83-95, maio/ago. 2021. Recebido em: 03/05/2021 
O grupo ContArte, em decorrência do cenário imposto pela pandemia, precisava pensar nas crianças e nos jovens que ficaram impossibilitados de irem à escola. Desse modo, buscou-se meios para contribuir com este tempo em que permaneceram em casa. Com 0 advento das atividades remotas, os contadores começaram a refletir sobre como seria contar histórias virtualmente, uma vez que, historicamente, esta prática estava fundamentada na tradição da narrativa oral, na qual os indivíduos contavam com a proximidade física para prestigiar a performance do contador de histórias.

No que diz respeito ao ato da narrativa, Cavalcanti (2002) nos fala que contamos histórias, principalmente "[...] para nos salvar pela palavra da nossa condição lacunar, faltosa e incompleta. Comunicar o visto, sentido e interpretado é, também, uma forma de dizer de nós e representar para o outro e por conseguinte dar sentido à vida" (CAVALCANTI, 2002, p. 23).

Nesse sentindo, com crianças e jovens em isolamento social, o grupo definiu novos meios para cumprir a missão de promover o acesso a leitura do literário por meio de vídeos de mediação de leitura, entrevistas e tutoriais de contação de histórias - conteúdo livremente disponibilizado nas redes sociais do projeto. Tal iniciativa teve como objetivo oportunizar aos espectadores o encontro com a leitura literária e a presença virtual do contador em sua casa, uma vez que "a leitura continua sendo uma experiência insubstituível, em que o íntimo e o compartilhado estão ligados de modo indissolúvel" (PETIT, 2013, p. 32).

Os contadores perceberam, no resgate e na promoção da leitura do literário, uma ponte que leva os espectadores - que também são leitores da história que está sendo contada a lugares distintos, encantados e inusitados, como meio de sair da realidade vivenciada, sem deixar a segurança do lar. Assim como Candido (1995), o grupo compreende que "uma sociedade justa pressupõe o respeito dos direitos humanos, e a fruição da arte e da literatura em todas as modalidades e em todos os níveis, é um direito inalienável" (CANDIDO, 1995, p. 191).

Candido (1989) também nos mostra que não é possível o ser humano, em sua vivência e em suas relações, viver sem alguma espécie de manifestação literária, já que a literatura transpõe a cultura, e se mantém presente de diferentes modos, como no folclore, nas lendas e nos cordéis, por exemplo. Para o autor,

[...] a literatura tem sido um instrumento poderoso de instrução e educação, entrando nos currículos, sendo proposta a cada um como equipamento intelectual e afetivo. Os valores que a sociedade preconiza, ou os que considera prejudicais, estão presentes nas diversas manifestações da ficção, da poesia e da ação dramática. A literatura confirma e nega, propõe e denuncia, apoia e combate, fornecendo a possibilidade de vivermos dialeticamente os problemas. (CANDIDO, 1989, p. 113). 
Com o advento da Web $2.0^{2}$ houve uma ampliação da oferta de suportes digitais, e por consequência, potencializou os processos de produção e divulgação de conteúdos, bem como possibilitou uma reinterpretação sobre as práticas de mediação tanto de saberes quanto de aprendizados nos meios virtuais. Segundo Lévy $(1993$, p. 7) "novas maneiras de pensar e de conviver estão sendo elaboradas no mundo das telecomunicações e da informática." Em meio a este cenário,

[...] os princípios de mediação e de leitura comuns e conhecidos em diferentes espaços, como bibliotecas, salas de leitura, ganham novas apropriações e contornos quando são os jovens que autonomamente planejam e elaboram atividades de incentivo, como ocorre na Internet (TEIXEIRA; COSTA, 2016, p. 5).

Desse modo, o projeto ContArte viu nos recursos oferecidos pelo ciberespaço ${ }^{3}$ um meio de promover a mediação da leitura do literário.

De suas raízes antigas até a atualidade, a arte de contar histórias modificou-se. Nos dias atuais, dependendo do contexto em que se encontra, uma mesma narrativa pode estar presente em diferentes suportes, como em vídeos do YouTube, páginas do Facebook, perfis do Instagram, blogs, podcasts (arquivo de áudio digital, frequentemente em formato $\mathrm{mp} 3$ ), entre outros.

Sendo assim, os contadores, inseridos em um novo cenário, adaptaram os conteúdos que produziram para os meios digitais. Em uma entrevista semiestruturada realizada de modo online com os bolsistas e as voluntárias do projeto, ao serem questionados sobre as estratégias adotadas pelo grupo para promover o acesso a leitura do literário em tempos de isolamento social, um deles responde (informação verbal)4:

Encantamento, literatura, poesia... Como abordar esses temas sem o calor do encontro presencial proporcionado pelo ContArte? Sabendo que os meios digitais têm se inserido cada vez mais no universo educacional, foi fácil perceber que essa seria a nossa maior aliada para as transformações. Porém, foi necessária uma adaptação do conteúdo para esses meios que, com frequência, estabelecem

\footnotetext{
${ }^{2}$ Segundo a Folha de S. Paulo, o termo Web 2.0 é utilizado para descrever a segunda geração da World Wide Web --tendência que reforça o conceito de troca de informações e colaboração dos internautas com sites e serviços virtuais. A ideia é que o ambiente on-line se torne mais dinâmico e que os usuários colaborem para a organização de conteúdo. (ENTENDA o que é a Web 2.0. Folha de S. Paulo, 10 jun. 2006. Disponível em: https://www1.folha.uol.com.br/folha/informatica/ult124u20173.shtml\#: :text=0\%20termo\%20Web\%202.0\%20\%C3\% A9,para\%20a\%20organiza\%C3\%A7\%C3\%A30\%20de\%20conte\%C3\%BAdo. Acesso em: 26 fev. 2021.)

${ }^{3}$ Lévy define ciberespaço "como o espaço de comunicação aberto pela interconexão mundial de computadores e das memórias dos computadores" (LÉVY, P. Cibercultura. 1. ed. São Paulo: Editora 34, 1999. p. 92).

${ }^{4}$ Entrevista online concedida pelo grupo ContArte, na plataforma do Google Meet (serviço de comunicação oferecido pelo Google), em setembro de 2020. Entrevistadoras: Cleide Jussara Müller Pareja e Maria Eduarda Policarpo.

Revista de Ciências Humanas, Frederico Westphalen - RS, v. 22, n.2, p. 83-95, maio/ago. 2021. 
contatos frios e impessoais com seus usuários. Por conta disso, o ContArte buscou manter a mesma energia sempre presente em suas apresentações presenciais em seu conteúdo digital, focado em manter a contação de histórias, mas também explorar novas possibilidades que surgiram com a tecnologia ao seu dispor. (Bolsista do Projeto ContArte em entrevista).

\section{OS NOVOS MEDIADORES}

O contador de histórias é aquele que traz o coração nas mãos.

Maria da Penha

A contação de histórias busca envolver o público com a escuta da história que está sendo narrada, para que ele perceba a leitura como um ato divertido e fruitivo, uma vez que 0 projeto ContArte procura difundir o livro como fonte de leitura, fruição e prazer. Refletindo sobre as possíveis distinções entre o prazer e a fruição, Barthes (2015, p. 20-21, grifo do autor) afirma:

Texto de prazer é aquele que contenta, enche, dá euforia; aquele que vem da cultura, não rompe com ela, está ligado a uma prática confortável da leitura. Texto de fruição é aquele que põe em estado de perda, aquele que desconforta (talvez até um certo enfado), faz vacilar as bases históricas, culturais, psicológicas, do leitor, a consistência de seus gostos, de seus valores e de suas lembranças, faz entrar em crise sua relação com a linguagem.

Nas atividades presenciais, os contadores, ao chegarem ao local de atuação, realizam a leitura com o livro à mão. Mesmo que a história esteja em sua memória, o livro deve estar com 0 contador a fim de ser visualizado pelo leitor. A voz, os gestos e o olhar são os elementos mais importantes na narração dramática. Zumthor (2000, p. 73) fala-nos de como o corpo, em especial "[...] as formas de expressão corporal dinamizadas pela voz [...]", traduzem a alegria e o prazer da leitura dos textos lidos pelo contador. Abramovich (2002, p. 16) reforça a importância de uma boa contação ao dizer que:

"Os momentos de contação de histórias devem fazer parte do cotidiano da criança de forma lúdica, agradável e significativa, pois as histórias passam para a criança uma imagem otimista de mundo, apontam os problemas e ao mesmo tempo mostram as possibilidades de resolução". (ABRAMOVICH, 2002, p. 16).

$\mathrm{Na}$ impossibilidade de contato presencial com o público, os contadores muniram-se de câmeras, tripés e aparelhos de iluminação improvisados, para assim, oferecer um conteúdo com 
a melhor qualidade possível. Sobre o novo formato de contação de história, um dos bolsistas do projeto relata (informação verbal): 5

A falta de público para quem está acostumado com a atenção de diversos olhares focados em sua apresentação pode ser um desafio a ser superado, já que o calor da plateia é inexistente. Dito isso, essa falta de público também trouxe uma liberdade no momento de desenvolver os diferentes conteúdos. Precisar ser o interprete, 0 cinegrafista, o figurinista, o iluminador, entre outras atividades puxou ao máximo 0 potencial criativo de cada um que, como é comprovado pelas apresentações, desenvolveram um trabalho digno da mesma qualidade já existente nas atividades presenciais. (Bolsista do Projeto ContArte em entrevista).

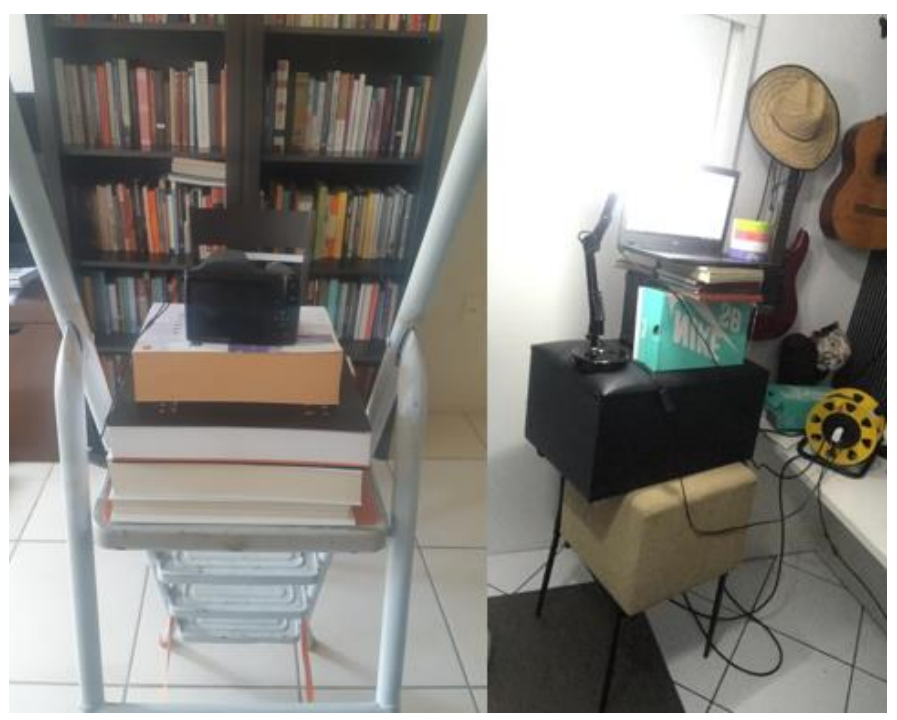

Figura 2 - Estúdios improvisados pelos bolsistas Fonte: Acervo dos bolsistas

Uma das voluntárias, ao dar seu parecer sobre a mudança de formato, nos conta (informação verbal)6:

A experiência da mudança de formato foi extremamente positiva. A todo momento os participantes estavam engajados em planejar e a criar conteúdos diferenciados para as plataformas digitais. Além disso, o trabalho realizado foi sempre construído na base do diálogo e na divisão de tarefas. Muitos se descobriram e se destacaram na edição dos vídeos, outros gostaram de produzir conteúdo frente às câmeras, e assim o projeto foi se desenvolvendo em colaboração mútua. (Voluntária do Projeto ContArte em entrevista).

${ }^{5}$ Entrevista online concedida pelo grupo ContArte, na plataforma do Google Meet (serviço de comunicação oferecido pelo Google), em setembro de 2020. Entrevistadoras: Cleide Jussara Müller Pareja e Maria Eduarda Policarpo.

${ }^{6}$ Entrevista online concedida pelo grupo ContArte, na plataforma do Google Meet (serviço de comunicação oferecido pelo Google), em setembro de 2020. Entrevistadoras: Cleide Jussara Müller Pareja e Maria Eduarda Policarpo.

Revista de Ciências Humanas, Frederico Westphalen - RS, v. 22, n.2, p. 83-95, maio/ago. 2021. Recebido em: 03/05/2021 


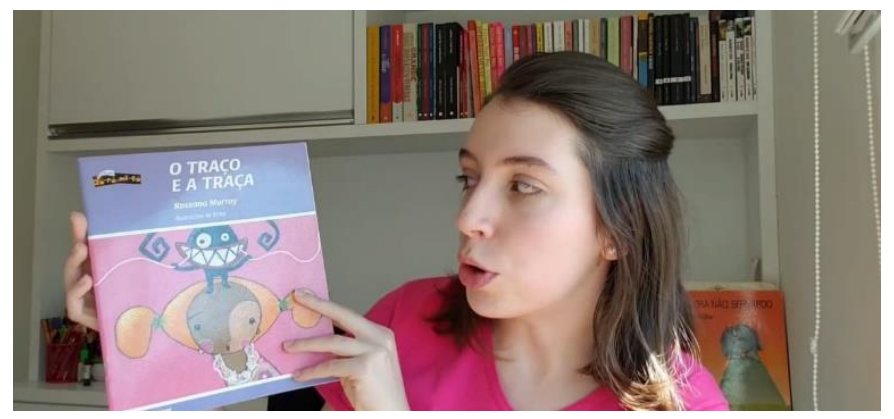

Figura 3 - Voluntária do projeto ContArte gravando uma contação de história Fonte: Acervo das voluntárias

As mediações de leitura e as declamações de poemas, propostas que foram cuidadosamente pensadas pelos bolsistas, organizaram-se em séries de vídeos. 0 nome Instante poético, por exemplo, foi escolhido para a série de declamações de poemas. 0 grupo também produziu quatro vídeos com a proposta de apresentar os aspectos que compõem o ato de contar histórias, uma vez que se discutiu desde a importância de contar uma história até a escolha e o preparo dela.

Ademais, na busca por oferecer um conteúdo diversificado, o projeto organizou o bloco Diálogos literários com ContArte, o qual consistiu em três entrevistas realizadas de forma virtual com professoras convidadas. Foram abordados os respectivos temas: "A importância da literatura na formação do educador"; "FNLIJ (Fundação Nacional do Livro Infantil e Juvenil) e a formação leitora de crianças e jovens" e "Educação estética e contação de histórias".

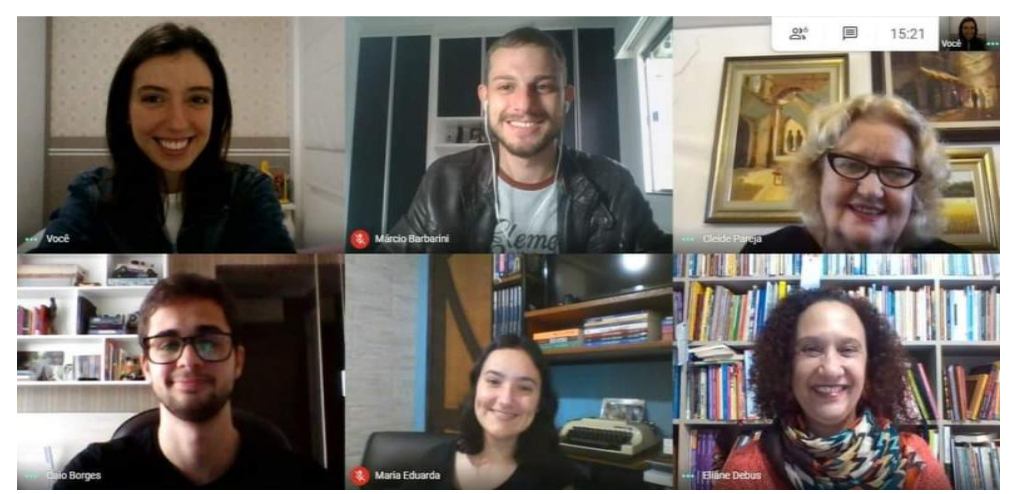

Figura 4 - Entrevista do bloco "diálogos literários com ContArte"

Fonte: Acervo das autoras

A respeito da variedade de conteúdos que foram disponibilizados pelo projeto, um bolsista afirma (informação verbal)7: "De banners a entrevistas, o conteúdo do ContArte nunca

\footnotetext{
7 Entrevista online concedida pelo grupo ContArte, na plataforma do Google Meet (serviço de comunicação oferecido pelo Google), em setembro de 2020. Entrevistadoras: Cleide Jussara Müller Pareja e Maria Eduarda Policarpo.

Revista de Ciências Humanas, Frederico Westphalen - RS, v. 22, n.2, p. 83-95, maio/ago. 2021. Recebido em: 03/05/2021 Aceito em: 15/06/2021
} 
esteve tão diversificado e inovador quanto nesse momento que, apesar de conturbado, tem se mostrado muito frutífero". (Bolsista do Projeto ContArte em entrevista).

\section{CONHECENDO O ALCANCE DAS ATIVIDADES NO MEIO VIRTUAL}

Todo o conteúdo produzido foi disponibilizado nas redes sociais do projeto ContArte, as quais é constituído por uma página do Facebook (anexo B), um perfil no Instagram (anexo A) e um canal no YouTube (anexo C). Diferente dos outros vídeos, as entrevistas não podem ser acessadas no Instagram, mas estão disponíveis em formato de podcast, no Spotify8. Para encontrar esse material é necessário buscar pelo título "Diálogos Literários" - conteúdo disponibilizado de forma gratuita (anexo D). Além disso, o grupo também enviou os links de suas produções para as escolas municipais da região via e-mail, e recebeu devolutivas como: "Muito obrigada! Divulgaremos os links aos professores e, com certeza, serão de muita valia, especialmente neste momento que estamos vivenciando" (BAIRROS, 2020).

$O$ ato de criar as publicações do projeto nas redes sociais, até a veiculação do conteúdo, fez-nos sistematizar um caminho para a construção de informações da pesquisa, de modo que estabelecemos quatro etapas em nossa rota. Primeira etapa: Divulgação do projeto nas redes sociais. Para isso, foi utilizada a página do projeto no Facebook e o perfil no Instagram; Segunda etapa: Escolha das histórias e dos poemas pelos membros do grupo. Terceira etapa: Gravação dos vídeos; Quarta etapa: Os vídeos foram enviados aos bolsistas responsáveis pela edição, os quais faziam os ajustes necessários de som, foco de imagem, além de fazer a inserção das vinhetas de abertura e de encerramento, locais que constam o logotipo do projeto. Ademais, eram feitos posts semanais para divulgar e relembrar as ações do projeto.

Ao observarmos esse processo de contar histórias e compartilhar a palavra poética com o mundo virtual, deparamo-nos com uma riqueza de possibilidades discursivas, uma vez que estávamos imersos em um equipamento de comunicação coletivo e, sobretudo, de relação social (LÉVY, 1999), mas agora com o objetivo de explorar e produzir conhecimento a partir desse campo.

Nesse movimento, os contadores passaram a refletir "para quem" estavam produzindo os conteúdos. Na busca por responder esse questionamento, identificamos no Facebook uma forma de acessar os dados quantitativos, já que essa rede social oferece informações sobre 0 gênero, a idade e a localização dos seguidores.

${ }^{8}$ Serviço de streaming de música, podcast e vídeo.

Revista de Ciências Humanas, Frederico Westphalen - RS, v. 22, n.2, p. 83-95, maio/ago. 2021.

Recebido em: 03/05/2021

Aceito em: 15/06/2021 
Os dados extraídos no dia 02/12/2020 nos indicam que os eixos geográficos com mais acessos que surgiram até então, estão localizados nas cidades de Itajaí (SC), Balneário Camboriú (SC), Navegantes (SC), Penha (SC), Camboriú (SC), Curitiba (PR), Florianópolis (SC), São Paulo (SP), Blumenau (SC) e Itapema (SC). Sobre a faixa etária, registramos uma maior concentração de seguidores e de pessoas que interagem com os conteúdos entre 35 e 44 anos, tendo maior a participação de mulheres. A segunda faixa etária mais presente está entre os $25 \mathrm{e}$ 34 anos também com o recorte do gênero feminino. Tais informações nos permitem dizer que a página tem sido acessada, majoritariamente, por mulheres adultas. No total, registramos 226 pessoas seguindo a página do projeto no Facebook.

\title{
Faixa etária e gênero
}

\author{
As pessoas que curtiram a sua Página estão \\ nesses grupos de idade e gênero. Esses \\ números são estimativas.
}

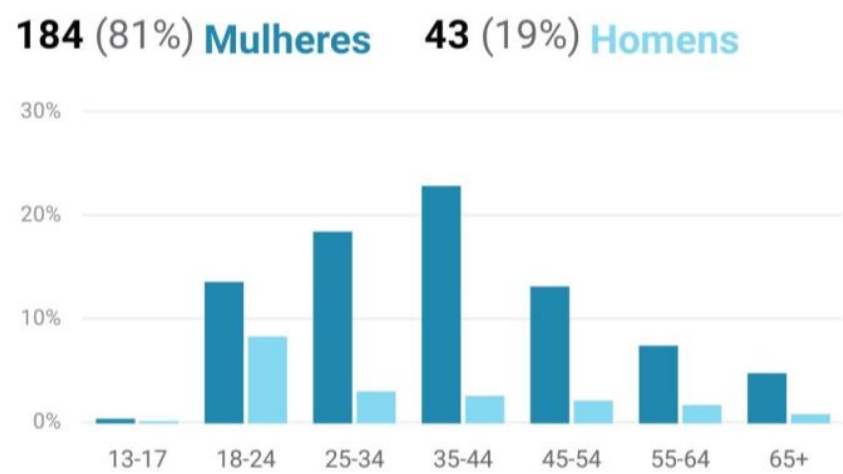

Figura 5 - Gráfico da faixa etária do público.

Fonte: Dados extraídos da página do projeto ContArte no Facebook.

Quando questionados sobre a possibilidade de o projeto alcançar novos públicos, um dos acadêmicos respondeu na entrevista (informação verbal) 9 :

\begin{abstract}
A minha mãe nunca tinha visto uma apresentação minha, ninguém da minha família tinha. Por conta de o foco ser as escolas, e esse já é um ambiente de muito público, ainda existia uma parcela grande de pessoas que poderiam ter contato com o trabalho do grupo e não tinham feito pela presença exclusiva dele nos espaços educacionais. Então, sim, eu acredito que adquirimos novos públicos e que a tendência agora é adquirir cada vez mais. (Bolsista do Projeto ContArte em entrevista).
\end{abstract}

\footnotetext{
9 Entrevista online concedida pelo grupo ContArte, na plataforma Google Meet (serviço de comunicação oferecido pelo Google), em setembro de 2020. Entrevistadoras: Cleide Jussara Müller Pareja e Maria Eduarda Policarpo.
} 
Outro ponto a ser destacado é sobre a duração desses materiais nas redes, uma vez que esses espaços virtuais vêm crescendo cada vez mais. Portanto, os vídeos continuarão circulando e estarão à disposição do público. "Tenho certeza que o conteúdo produzido pelo ContArte pode ser usado por públicos diversos, incluindo docentes, estudantes e entusiastas do literário", afirma outro bolsista do projeto ao ser entrevistado.

Ao fim do ano de 2020, o grupo disponibilizou um total de 12 vídeos de mediação de leitura do literário, 11 vídeos de declamações de poemas e 12 vídeos que compõem o bloco das três entrevistas. Na última coleta de dados realizada no dia 21/01/2021 observamos que o canal do YouTube contava com 298 visualizações. Em um levantamento na página do Facebook feito no dia 21/01/2021, indicava que nos últimos 28 dias (25/12/2020 a 21/01/2021) a página, que contava até então com 229 curtidas, havia alcançado 54 pessoas (o número de alcance consiste no número de pessoas cujas telas foi exibida em qualquer publicação da página. Esse número é uma estimativa e não pode ser preciso). Já o perfil no Instagram, contava com 49 publicações e 156 seguidores, segundo os dados levantados no dia 21/01/2021.

\section{TECENDO AS CONSIDERAÇÕES FINAIS}

Diante 0 exposto, é possível concluir que as novas estratégias possibilitadas pelo espaço virtual são boas opções para a divulgação da arte de mediar histórias.

\footnotetext{
Durante muito tempo a memória era o único recurso de armazenamento e transmissão de conhecimento. Era através das narrativas orais que as pessoas se apoderavam de conhecimento. Eram os narradores os responsáveis por discutir fatos, encadear acontecimentos, perpetuar crenças e manter as tradições. (BAPTISTA, 2017, p. 4)
}

Nessa perspectiva, os contadores viram no ato de narrar em um espaço virtual uma alternativa inovadora, não só de continuar a contar histórias, mas também de promover o gosto pela leitura do literário. Sobre essa experiência, um dos bolsistas compartilha (informação verbal) $)^{10}$ :

10 Entrevista online concedida pelo grupo ContArte, na plataforma Google Meet (serviço de comunicação oferecido 
Por mais que exista a falácia de que toda mudança é para melhor, nesse caso a frase se faz verdadeira. 0 movimento de adaptar o conteúdo já existente para um novo formato retirou o grupo de qualquer zona de conforto que poderia existir e 0 motivou a trabalhar em novos projetos que saciassem a sede daqueles que têm 0 ContArte como seu companheiro durante o isolamento social. (Bolsista do Projeto ContArte em entrevista)

Como diria Joana Cavalcanti (2002), com a leitura é possível ampliar o universo interior e alcançar o complexo conjunto dos sentimentos humanos. Jogar com o simbólico, com 0 metafórico durante a leitura é convidar o leitor a despertar sua sensibilidade. A arte da literatura pode gerar por meio de seu jogo estético a abertura para novos entendimentos da vida, para a ampliação da visão de mundo.

Deste modo, conclui-se que, apesar das muitas mudanças e adaptações impostas pela pandemia, o grupo viu no isolamento uma possibilidade de reinventar-se, mas sem interromper 0 seu processo de difundir a leitura literária. Como diz Larrosa (2002, p. 24), "a experiência, a possibilidade de que algo nos aconteça ou nos toque, requer um gesto de interrupção [...] suspender 0 automatismo da ação, cultivar a atenção e a delicadeza [...]".

Ademais, as redes sociais digitais, além de um recurso de comunicação, são um registro de memória coletiva, pois recorremos a elas para nos expressar e registrar o que vivemos. Uma vez que "o contador de histórias é este sujeito que na atividade de contação pode mobilizar o leitor a entrar no universo literário" (NEITZEL; CARVALHO, 2016, p. 152), o grupo ContArte espera que com o conteúdo disponibilizado na internet mais pessoas possam se encantar com a leitura do literário.

\section{REFERÊNCIAS}

ABRAMOVICH, F. Literatura Infantil: Gostosuras e bobices. São Paulo: Scipione, 2002.

BARTHES, R. 0 prazer do texto. 6. ed. São Paulo: Perspectiva, 2015. 78p.

BAIRROS, N. Produções do ContArte - Tempos de pandemia [mensagem pessoal]. Mensagem recebida por <natalina.bairros@edu.bc.sc.gov.br> em 10 de set. de 2020. Acesso em 06 de nov. de 2020.

BAPTISTA, E. S. (2017). Uso da contação de histórias no atendimento psicopedagógico. Diálogos Interdisciplinares, 6(2), 1-12. Disponível em: https://revistas.brazcubas.br/index.php/dialogos/article/view/308. Acesso em: 06 nov. 2020.

CANDIDO, A. Vários escritos. $3^{\mathrm{a}}$ ed. revista e ampliada. São Paulo: Duas Cidades, 1989.

CANDIDO, A. Vários escritos. Rio de Janeiro: Ouro Sobre Azul, 1995. 
CAVALCANTI, J. Caminhos da literatura infantil e juvenil: dinâmicas e vivências na ação pedagógica. São Paulo: Paulus, 2002.

LARROSA, J. Tremores: escritos sobre experiência. Belo Horizonte: Autêntica Editora, 2002.

LÉVY, P. As tecnologias da Inteligência. O futuro do pensamento na era da informática. 1. ed. Rio de Janeiro: Editora 34, 1993.

. (1999). Cibercultura. São Paulo: Editora 34.

NEITZEL, A. de A.; CARVALHO, C. A movência do leitor na leitura do literário. In: NEITZEL, A. de A.; CARVALHO, C. (Orgs.). Mediação cultural, formação de leitores e educação estética. Curitiba: CRV, 2016. p. 143-157.

PETIT, M. Os jovens e a leitura: uma nova perspectiva. São Paulo: Editora 34, 2009.

TEIXEIRA, C. S.; COSTA, A. A. Movimento Booktubers: práticas emergentes de mediação de leitura. Texto Livre: Linguagem e Tecnologia, Belo Horizonte-MG, v. 9, n. 2, 2016. Disponível em: https://periodicos.ufmg.br/index.php/textolivre/article/view/25487. Acesso em: 10 fev. 2021.

ZUMTHOR, P. Performance, recepção e leitura. São Paulo: EDUC, 2000. 